\section{What hue are you?}

With the power to influence your mood and characterise your image, it is important to carefully consider colour in your practice. Personal preference is naturally a key factor in colour selection, and an important decision to make when investing in a surgery chair that will see you through years of practice. There are also psychological connotations to consider: the traditional calming tones of blue, in contrast to the warm, fun vibes of a fuchsia pink.

Belmont offer three types of upholstery - Standard, Ultrasoft and UltraSoft Pro. There is a diverse colour range within each category to ensure you get just the right shade to complement your practice's decor.

The Standard upholstery range comprises ten colours; each is smooth

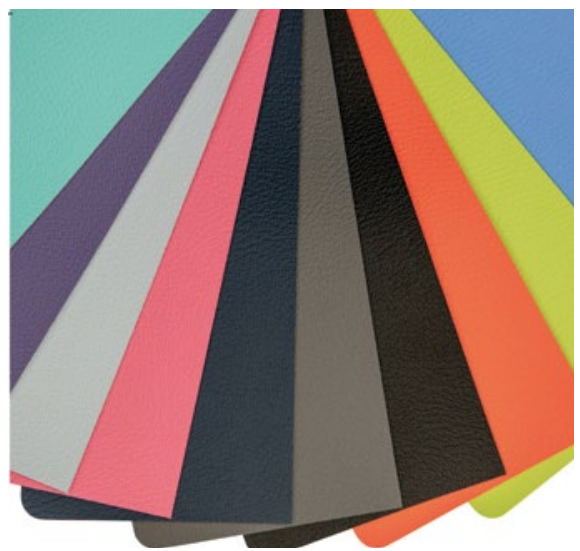

to touch and easy to maintain as the fabric is seamless. You can choose from neutral tones, such as the popular 'Light Gray' to more vibrant colours, such as 'Scarlet Red'.

Belmont chairs are also available in an Ultrasoft finish. As the name suggests, the look and feel of this fabric exudes luxury and comfort. Arguably, a comfortable chair is a prerequisite for a relaxed working environment, especially when patients are undergoing lengthy treatments. Within this range are 37 colours, enabling you to tailor your colour choices.

For those who want to experience the ultimate in luxury there's Ultrasoft Pro, which has the added reassurance of ink and denim resistance as well as antimicrobial protection. This range is available in 33 different shades and contains classic, cool and earthy tones, as well as warm and vibrant options for those who are big on colour!

Aesthetics obviously need to be matched with functionality, and likewise in this respect, Belmont will not disappoint.

\section{Keeping things simple}

Panavia V5 is designed to make your restorative procedures simple.

It covers a huge array of indications so you only need one product for all your cementation needs. It also comes in an automix syringe that facilitates easy, time-saving application, with simple removal of any excess cement.

Panavia V5 contains MDP adhesive monomers to ensure excellent and longlasting bond strength to zirconia and is available in five shades for superior aesthetics. In addition, its low film thickness of just 12 microns allows a tight fit and reliable marginal seal to reduce sensitivity and promote patient comfort.

Keep things simple with Panavia V5. Order through your usual dealer or from J\&S Davis directly.

For more information on the industryleading products available from J\&S Davis, visit www.js-davis.co.uk, call 01438747344 or email jsdsales@js-davis.co.uk.

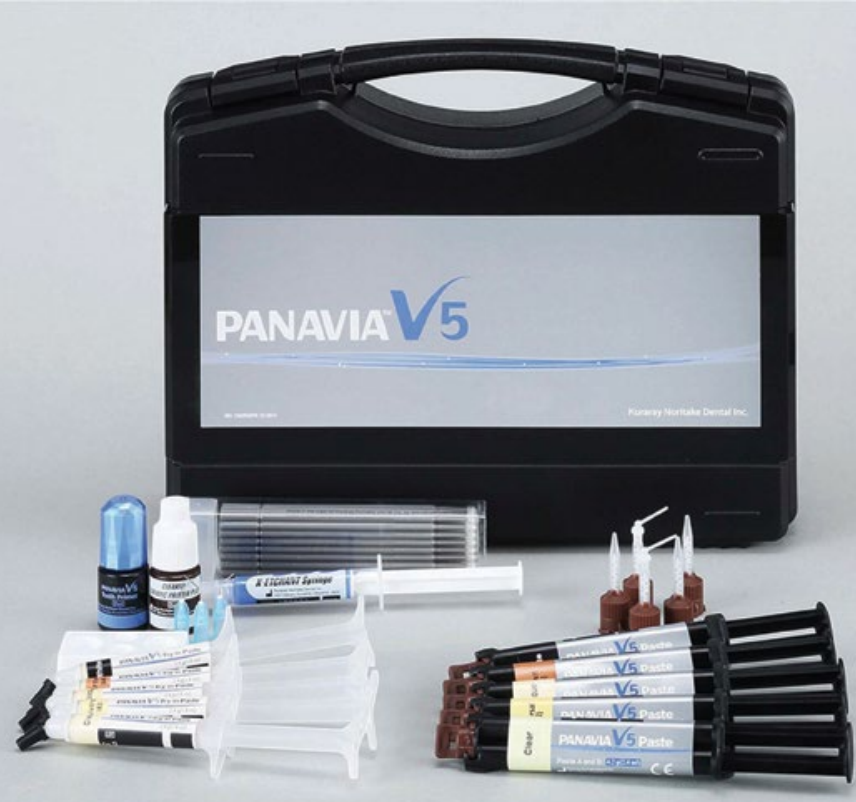

New tax year, new

\section{opportunities}

With the new tax year underway, there's no better time to review your finances and consider tax efficient investment vehicles to maximise your hard-earned money. For help getting the best results contact the team of Independent Financial Advisers at money4dentists.

With multiple awards to its name

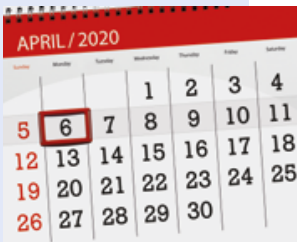
and over half a

century of experience, money4dentists can work with you to establish a personalised plan that meets taxation expectations, supports your financial objectives and boosts your financial position.

The team also ensures that you are kept up to date with taxation changes that might impact you and your portfolio of investments, giving you one less thing to worry about.

Book your free consultation today to get started.

For more information call 0845345 5060 or 0754 DENTIST.

Email info@money4dentists.com or visit www.money4dentists.com. 